\title{
Emotional Introspection: The Politics and Challenges of Contemporary Migration Research
}

\author{
Ninna Nyberg Sørensen
}

\begin{abstract}
INTRODUCTION
Hands that usually write meticulous field notes lie still on the table in the room where a seasoned researcher-recognised among peers for his fieldwork in places marked by conflict-has agreed to meet and share his experiences. Seconds ago, the same hands were eagerly gesturing to illustrate a compelling experience in the field. He now tells me about an encounter with a group of recently arrived, internally displaced women with terrible pasts. While narrating details about their escape from a violent attack by an armed group terrorising their hometown, one of the women suddenly placed her child in his arms and begged him to take it to Europe, "so that the child at least may have a chance". Her words- "there's nothing left to be done here, we're finished"-torment his memory. Making a shift from a passionate researcher to a human being
\end{abstract}

N. N. Sørensen $(\bowtie)$

Danish Institute for International Studies (DIIS), Copenhagen $\varnothing$, Denmark e-mail: nns@diis.dk

(C) The Author(s) 2022

M. Sandberg et al. (eds.), Research Methodologies and Ethical Challenges in Digital Migration Studies, Approaches to Social Inequality and Difference, https://doi.org/10.1007/978-3-030-81226-3_8 
momentarily stripped of his defences, the still hands and empty gaze reveal how emotionally disturbing fieldwork can be.

"It's the combination", he says, referring to the exposure to human suffering, personal expectations of making a difference, and very narrow opportunities to do so. "It's just so incredibly insurmountable". Unlike when he was younger and convinced that his work could make a difference to the quality of life of his interlocutors, the accumulation of instances of "not being able to do anything" occasionally fills him with hopelessness, desperation, and, in his eyes even worse, cynicism.

Scholars who conduct field research among people in difficult circumstances are often confronted with immense hardship and ethical complexities. This is notably the case in contexts where gross inequality, poverty, violence, and physical vulnerability abound, and protective social infrastructures are inadequate and unevenly accessible (Plüg and Collins 2018). As qualitative research is predicated on establishing trusting relationships with groups and individuals in local environments, field-based research in fragile situations and insecure places, almost by definition, means putting ourselves not only physically at risk, but also emotionally on the line (Goldstein 2014). Risk of emotional distress certainly applies to migration researchers who increasingly encounter traumatic events and narratives associated with involuntary immobility or clandestine travel across borders in attempts to escape poverty, violence, or persecution. The migrant experiences that often leave the heaviest imprint are those of migration gone terribly wrong: stories of not succeeding in crossing the border; of being intercepted and forcefully returned along the routes; of, after years of living undocumented lives abroad, being repatriated from refugee camps or becoming "victims of human trafficking"; or stories told by relatives searching for loved ones who disappeared before reaching their destination. Failure to connect such experiences to the effect they have on our work and personal lives will inevitably affect the way we view the world and ourselves in it and, by implication, our ability to carry on producing sound research.

Anthropologists and others applying ethnographic methods have an ample vocabulary for how we affect or impose ourselves on the field. When it comes to how experiences in the field affect us, the conversation gets quieter (Kristensen 2017). This fragmentation is partly a result of the unresolved role of emotions in research (Fleetwood 2009), partly a consequence of a lack of institutional structures that seriously deal with these 
matters, and partly an effect of broader patterns of unequal power relations between researchers, the people whose lives we wish to engage with, learn from and document, and the local brokering researchers engaged, without whom much research could not be carried out (Abedi Dunia et al. 2019; Abedi et al. 2020). And it is by no means an easy conversation to engage in; on the few occasions when we expose the often-brutal reality our research entails, it can occasion serious digestive problems among ethics committees, local partners, colleagues, and, not least, ourselves due to personal ambivalence about the relevance and "place" of revealing our emotions publicly, with or without good cause (McLean 2011). It is therefore no surprise that migration researchers occasionally face emotional challenges comparable to those encountered by colleagues in fields such as peace and conflict studies, or by staff working for humanitarian organisations, among whom high rates of anxiety, depression, compassion fatigue, secondary traumatic stress, or vicarious trauma are found (Grimm et al. 2020). We just rarely talk about it and tend to ignore symptoms of compassion fatigue or vicarious trauma when our spirits get low. Some, then, go down with "stress".

Over the past ten years, the question of physically "surviving fieldwork" has become a central concern in research (Shiram et al. 2009; FelbabBrown 2014; Theidon 2014; Grimm et al. 2020; Mac Ginty et al. 2021). In response, many research institutions have taken steps to reduce fieldwork risks and enhance safety. Safer research is generally understood to involve predeparture preparation and, when deemed necessary, some sort of hostile environment awareness training (so-called HEAT courses). The safety of interlocutors is generally monitored by committees overseeing compliance with core ethical principles such as informed consent, "do no harm", and data protection and storage (Mackenzie et al. 2007; Hugman et al. 2011). Debriefing structures are sometimes set up, offering opportunities to offload shattering experiences, inspired by those implemented by humanitarian actors (Martin-Ortega and Helman 2009). While no one can be against preparing researchers for safety hazards, critical voices argue that one-sided attention to physical security risks encouraging an "us versus them" attitude (Lake and Parkinson 2017) that, furthermore, may contribute to increasing the distance between researchers and our interlocutors (Grimm et al. 2020). Another problem with the one-sided focus on physical safety pertains to the possible contribution to undifferentiated, and at times exaggerated, negative stereotypes of dangerous settings (Woon 2013), contributing to the creation of a "no-go world" of global 
distancing and endangerment (Andersson 2019). These concerns resonate well with Sara Ahmed's suggestion that judging places and bodies as suspicious, dangerous, or something to be feared may have fatal consequences for those inhabiting them (Ahmed 2014). Awareness of these critical issues does not exactly make the conversation easier.

Attempts to promote safer field research attuned to the reality of the social sciences have been slow to incorporate emotional challenges and well-being, including not only that of contracting researchers institutionally located in the Global North but also of facilitating researchers and other participants in the Global South (Môcnik 2020). Acknowledging that emotional well-being is closely connected to physical security, and that neither of these concerns can be limited to the contracting researchers only, this chapter aims at discussing the emotional challenges involved in contemporary field research among migration researchers. The chapter highlights the contexts and institutional structures surrounding our research, the new opportunities for conducting digital research along with the associated effects of digital availability, and what can be done prior to, during, and after going to the field to maintain emotional engagement while avoiding occupational hazards of compassion fatigue, burnout, or secondary traumatic stress among all those involved.

Before embarking on these issues, I briefly present the methodology on which my reflections are based and describe the current context for conducting migration research. Drawing on fieldwork experiences shared by colleagues, I then present some of the emotional challenges encountered. I conclude by highlighting some of the practices that have proven useful for recognising emotions as intrinsic to field encounters while simultaneously helping to reduce the negative effects and personal costs associated with fieldwork. Since symptoms of vicarious trauma and burnout among researchers are well described in the psychological literature, my emphasis is on the participating researchers' personal experiences, explanations, and suggestions for ways ahead, rather than on the occupational hazards resulting in headaches, emotional extraction, sleep problems, drained immune systems, altered perceptions of reality, selfblame, cynicism, and tunnel vision that most have experienced in one form or the other. ${ }^{1}$ 


\section{A Note on Methodology}

After years of institutional preoccupation with research ethics and the physical safety of researchers and their interlocutors, I have discovered that a "loss of heart" among colleagues often had as much to do with being exposed to seemingly hopeless situations as with being provoked by working in dangerous settings. Before I got there, I took a detour around occupational stress, which seemed to be prevalent among colleagues, especially $\mathrm{PhD}$ students, who are almost expected to succumb to stress during their doctoral research. There is much to ponder here, which, beyond questions of the "illegitimacy" of feelings among researchers and inadequate training in dealing with them, also includes the generalised belief-whether true or not-that emotionally "tough" researchers stand a better chance in the struggle for (limited) future permanent positions. Thus, it may be regarded as more legitimate to give in to the pressures of academia than to the emotions fieldwork may have provoked.

The empirical basis for the experiences related here stems from two years of dialogue with colleagues and more structured interviews with ten selected scholars. The researchers contributing their experiences are diverse in terms of gender, academic trajectory, national background, and institutional location. Only one researcher, however, is physically located in the Global South, whereas the rest are attached to Danish or other European research institutions. Their disciplinary backgrounds vary, spanning anthropology, sociology, geography, history, psychology, and development studies, with different traditions of including/excluding emotional aspects in the research process. All have conducted one or more long-term periods of fieldwork in insecure places among people subjected to extreme hardship related to some form of migration, be it among internally displaced persons (IDPs); people fleeing poverty or war involving genocide; people trapped in refugee camps, asylum and detention centres; or smuggled and trafficked migrants. While many of the migrants and refugees interviewed by my conversation partners have managed to find better and more secure lives over the years, others have ended up in prison, died along the routes, or continue to eke out an existence. The disastrous consequences of deterrence-based migration policy and practice-that deliberately ignores the plight of migrants in distress in order to dissuade others - are not limited to any particular region. The participants' field experiences stem from Africa, the Middle East, Asia, and Latin America, as well as from sites within or bordering Europe and the 
United States. This diversity is not totally random. Several are present or former colleagues; others are people I have met at conferences or through other forms of international research collaboration. While I considered approaching researchers outside my personal networks to avoid "insularity", upon reflection this probably would have led to less focused and less intimate conversations. I already knew about (some) of the emotional challenges the participants had faced; they knew me well enough to feel confident talking about less "heroic" moments of their careers.

All participants were given advance information about the aim of my project and sent a rough thematic "guide" about issues of interest, including specific, demanding fieldwork incidents, whether we are prepared for such incidents to occur, how we tackle emotional challenges during and after fieldwork, and the degree of institutional support in pre-fieldwork training, supervision and-when necessary-psychological counselling during and after completed fieldwork. Everyone was encouraged to make constructive suggestions about what we can do better, both as individuals and as research institutions. Finally, more established researchers were asked to reflect upon whether their field has become more emotionally challenging over the years, an issue I find particularly important in efforts to avoid over-simplification (e.g. that younger researchers, due to a lack of experience, are more prone to emotional hardship or that burnout among older researchers is necessarily due to overexposure).

Our exchanges lasted from one to two hours. Some took place in my or their offices, others in places outside our working environments. Three conversations were held virtually. On all occasions, we discussed the purpose of dwelling on emotional hardship in research before oral informed consent to participate was granted. All conversations were taped and fully transcribed by me. The participants were offered the opportunity to develop statements they found needed further explication than in the transcripts. They have also been offered the opportunity to see a draft of this chapter before publication. Finally, all have been granted anonymity and no names therefore appear in what follows.

Despite my focus on personal experiences, several participants reflected not only on their own but also on situations affecting local brokering partners, be they interpreters or fellow researchers contracted for data collection. Instead of being "oblivious to privilege and positionality" (Abedi Dunia et al. 2019), most were painfully aware of having had 
access to insurance or counselling structures not available to local partners. Indeed, frustrations over unequal working conditions have, in some cases, exacerbated the emotional strain during fieldwork. Such frustrations have also been found among researchers from the Global South who, for instance, study for their PhD degrees at universities in the North and from that position conduct field research in their countries of origin (Kalinga 2019; Turner 2010).

\section{Conducting Migration Research at the Present Moment}

Migration research is a diversified field concerned with the drivers, processes, and outcomes of proactive ("voluntary") and reactive ("forced") manifestations of human mobility. Those involved in the field increasingly agree that the distinction between economic and political forces motivating migratory movements is difficult to uphold (Richmond 1994; Stepputat and Sørensen 2014). Similar critical reflections on migration as exceptional human behaviour have begun to take shape (Shah 2020), just as studies of immobility have gained traction in migration research (Carling 2002; Lubkemann 2008). Human mobility, especially over long distances, has always been subject to contestation. Studying these processes ethnographically in real time has more often than not involved dilemmas of privilege and disadvantage, attention to asymmetric and unequal power relations and, in the best of cases, concerted reflection on ethical challenges along with methodological and political investment in research (Castellanos 2019).

Many challenges befall scholars who explore contemporary migration phenomena. On top of the power dynamics between researchers and those whose lives are at stake, the representation, dissemination, and discussion of research results increasingly take place in politicised fora. Public discourse and the media play a major role in framing perceptions of migration. When framed as crisis, migration experiences tend to acquire a specific temporal dimension, largely disconnected from history and related events, that not only directly shapes policies but also favours some research results over others (Menjívar et al. 2019). Indeed, researchers have far better access to policy circles and media outlets than disadvantaged interlocutors, but what we contribute and how that contribution resonates with politics vary according to the prevailing narrative of migration. Or, put differently, conducting migration research may be perceived 
as more challenging during times when research results have little resonance among political decision-makers and the general public, when the lines between "for" and "against" migration are more sharply drawn, or when humanitarian considerations become subordinated to wishes for control and restraint. Thus, emotional experience cannot be separated from the historical moment and social environment in which is embedded (Åhåll 2018).

Crisis rhetoric and images of "unprecedented flows" have led to new restrictions on human mobility, manifested in ever stricter border control mechanisms or in what Ruben Andersson (2019) has called a "posthumanitarian moment of harsher deterrence". Deterrence mechanisms include the extension of border surveillance and cooperation between coast and border guards with migrant-sending countries (de facto illegalising not only the right to enter a given country but also to leave your own), the use of suffering as a means of deterrence, the deployment of security forces in border and desert areas (to perform "pushbacks" and "pullbacks"), the outsourcing of migrant detention and removal to private security companies, and the criminalisation of assistance (Sørensen and Plambech 2019; Distretti 2020).

Alongside the geopolitical changes affecting migrants' and asylum seekers' travel, transit, and arrival conditions, there are questions of extortion, violence, abuse, enslavement, and, in the worst cases, disappearance or death along the routes that demand attention (Sørensen and Huttunen 2020). Such changes and developments are reflected in the places where researchers conduct fieldwork, including insecure border areas or other hostile environments. They are also reflected in the situations in which fieldworkers find their interlocutors. As global inequality is currently manifested in unequal access to mobility and fundamental human rights, many of these situations involve indefinite positions of "not arriving" and "not becoming" (Khosravi 2018), meaning that many migrants and refugees are found in seemingly hopeless situations. It is therefore no exaggeration to say that migration research is currently challenged by increasing media attention to, on the one hand, imagined or real increases in the numbers of migrants arriving at the borders of reluctant hosts, and, on the other hand, traumatic migrant experiences of dramatic journeys, pushbacks, detections, detentions, deportations, and gross human rights violations along the way.

With so much insecurity and human suffering at stake, the central ethical and methodological challenges in undertaking migration research 
demand renewed attention. Research involving refugees and IDPs has acknowledged the politically complex, difficult, and often insecure places in which fieldwork among vulnerable participants is carried out. This has occasioned ethically reflexive calls for ways to move beyond "do no harm" as a standard for research design and conduct (Mackenzie et al. 2007). However, there has been less concern with the emotional implications and effects of conducting research in insecure places among migrants in extremely difficult situations.

Nonetheless, a small but growing emphasis on the ethical challenges and emotional politics involved in conducting fieldwork on migrationrelated topics in times of intensified border controls is beginning to emerge, often building on personal experiences in the field and published in blog posts. Writing on secondary trauma, Mary Bosworth notes that her research in immigration detention centres is "unsettling" and sometimes "overwhelming", leading to psychological effects such as sleeplessness, anxiety, and palpitations. While Bosworth depicts these emotions as hers to manage and accepts them as an inescapable part of where her work as an experienced criminologist takes her, she finds it crucial to share accounts of challenges and how to overcome them with doctoral students and postdocs, who might be entering the field for the first time (Bosworth 2017). From the position of a younger researcher embarking on field research, Tamara Last describes how conducting fieldwork on border death led to symptoms of depression and the development of PTSS in herself and among her co-workers. Although such experiences have a high personal cost, when subjected to critical (auto-)reflection they may lead to methodological suggestions for reducing vicarious trauma stemming from emotionally disturbing research, including ideas for integrating effective monitoring and intervention protocols into the research design from a very early stage (Last 2020; see also Môcnik 2020).

Attention to the role of emotions in fieldwork provides a pathway to appreciate the imprint of personal relations and feelings that shape research outcomes and the knowledge produced. We go to the field to get a more nuanced understanding of local and geopolitical processes, to enhance the visibility of grounded and alternative visions, and hopefully thereby become capable of decentring assumptions that are taken for granted. "Emotional fieldwork", Chih Yuan Woon argues, "opens up the researcher to different emotional engagements and connections with his/her respondents, which in turn allows for critical reassessment of issues pertaining to danger, ethics and responsibility" (Woon 2013, 32). 
However, even if such insights provide a powerful argument against positivist research ideals and effectively deconstruct objectivity and distance in favour of emotional engagement, they also hint at the somewhat false dichotomy between the physical and emotional safety of field-working researchers. This has been a recurring theme in the conversations that inform the following discussion.

\section{Field-Related Exposure, Institutional DRIVERS, AND EMOTIONAL VULNERABILITY}

Field-based research often takes us to places that are unimaginable before arriving and unpredictable while there. While predominantly presented as a professional practice, engaging in fieldwork often turns out to be a physical, personal, and emotional experience (Fleetwood 2009). This also applies to fieldwork conducted in the countries we reside in-for example when conducting research in refugee reception or migrant detention centres-with the difference that the researcher can return to her or his home on a daily or weekly basis and maintain direct social contact with family, friends, and colleagues. However, the ability to reach out is not necessarily directly connected to physical distance between "home" and "field".

\section{Insecure Places and Hopeless Situations}

In terms of field-related, emotionally distressing experiences, the participants in this study distinguished between anxiety provoked by insecure places and discouragement provoked by exposure to hopeless situations. Talking about both proved equally transgressive for most. Anxiety leading to emotional distress was partly experienced as related to physical dangers abroad such as the risk of falling victim to violence, kidnapping, or traffic accidents, whereas anxiety grounded in the difficulty of being able to distinguish what is dangerous in unfamiliar surroundings constituted another group of factors. The daily unpredictability coupled with doubts about whom to trust, feeling monitored by authorities or parallel criminal structures, or feeling manipulated by gatekeepers, were all seen as contributing to distress in the field and the development of stress symptoms upon return, leading to sick leave (three cases) and, in the worst case, vicarious trauma upon return (one case) or even years after leaving the field (another case). 
Discouragement provoked by exposure to desperate and hopeless situations was easier to acknowledge on a personal level but equally difficult to talk about. "You cannot afford to succumb to the suffering of others. They have to stay and live with it all the time", said one participant. While doing research among deported migrants in the Global South, an experienced researcher noted: "Well, they live there all the time, and I can leave. So, I have many discussions with myself that are both personal and political. Can I allow myself as a white, middle-class person to say that I do not dare be in a certain place that others are prevented from leaving?".

Many did not receive much guidance before embarking on their first fieldwork. They were familiar with qualitative interview techniques, participant observation, and so on from their basic academic training; but had never spoken to their $\mathrm{PhD}$ supervisors or senior colleagues about the potential emotional strain of conducting fieldwork. Along with the lack of preparation for the emotional impact of fieldwork on their wellbeing, younger colleagues also related that they did not have much contact with their supervisors during often-lengthy fieldwork periods. Many, moreover, perceived that it was expected of them to have as little contact as possible with their personal social networks while abroad, to facilitate a deeper engagement with the places and people among whom they worked. Finally, one participant mentioned that supervisors involved in collaborative projects may become vicariously traumatised by the research themselves, which creates dysfunctional supervision and support structures.

\section{Emotional Rewards}

Although most could talk about emotionally challenging situations in the field, hardly any started the conversation there. On the contrary, participants commented that they had felt enriched, and naturally also saddened, by what their interlocutors had gone through, but even so, they felt professionally and personally rewarded by the, often intense, meetings with other human beings. "People always expressed contentment with my being there, of being asked to tell their story", a researcher explained. In his experience, many hard stories led to some form of relief, for the person telling the story as well as for the researcher tasked with making the story known. The latter, of course, places an immense burden on the act of bearing witness (Appelbaum 2008) that may manifest in the process of analysis and writing. To this researcher, however, allowing himself to 
be emotional in the field and to not be afraid of his personal vulnerability was, furthermore, an essential methodological necessity: "I cried during several interviews, and that was what opened up ... in the moment people saw my emotional reaction, they threw away their reservations and opened up completely". Allowing ourselves to feel hurt during fieldwork is therefore not only essential to maintaining a healthy emotional self but also a methodological tool for gaining "access".

Another researcher, who for much of his lengthy career has worked with violent conflict, IDPs, and international refugees, expressed a slightly different dynamic: "After all, we are talking to the survivors, who are often capable of turning the past into some sort of heroic narrative of how they managed the situation". In his view, then, the reward of fieldwork consists in providing interlocutors with a space to create meaning and take on an active role in an otherwise horrific situation.

Such spaces are not one-way, but often reflect on the researcher's emotional well-being: "I think that I grew personally from working with vulnerable people", a mid-career researcher underscored. "And this is not because I compare my own situation to theirs. It is rather because it is in the meeting between human beings that you gain energy ... you know, the opposite of compassion fatigue". She further explained:

I believe it is all about accepting that you move through different spaces but maintain the same ethics in them. It is a form of relativism where you accept that we have very different conditions, but basically we are the same. And always respect the persons you work among, never say no, but always accept what someone offers you, you know, somehow being able to show that you are able to see the resources people have. Even in the darkest of situations.

Others nevertheless ended up pointing to the ambivalent place of emotions in research and the institutional structures that prevent taking emotions seriously into account. "Are you really allowed to have feelings in research?" was a frequently asked question, as were statements such as "I believe emotions continue to be illegitimate in research environments" or "ideas of objectivity still prevail and prevent us from bringing our personal emotions to the fore". Giving the discussion a gendered twist, one could further argue that emotions remain associated with the personal, the body, and the feminine, whereas the objective, the mind, and the masculine continue to prevail, even in the sciences that are 
supposed to be “social” (Åhåll 2018). Younger colleagues pointed to a dire lack of institutional attention to emotional stress both prior to, during, and to a lesser extent after completing their fieldwork, while postdocs searching for permanent employment expressed a fear that showing "emotional weakness" could be used as a sorting mechanism when filling new positions. "I feel that you gain recognition by daring to go to difficult places", one discussion partner stated, whereas another felt that "to be emotional is to be vulnerable and vulnerability is not viewed as a resource when it comes to hiring permanent staff". Younger researchers therefore felt that they could talk to colleagues on their own level, but not necessarily to their supervisors or other senior researchers in the institutions to which they are (temporarily) attached.

\section{Conducive Institutional Cultures?}

Institutional structures reflect power relations with respect to project approvals, grants, and, ultimately, promotions along the career track. Apart from how they are structured, institutional cultures are co-created by how researchers represent themselves and interact with each other. Mirroring the "Bang-Bang effect" among war reporters and photographers (Marinovich and Silva 2000); Kimberly Theidon (2014) refers to the practice of sharing who has seen the goriest scenes (the most battered bodies, the heaviest rain of bullets, or other dangers) as the "horror index" within peace and conflict studies. The stories I have encountered among migration researchers have not necessarily been gory but nevertheless may have contributed to generating what I, for lack of a better concept, term the "Indiana Jones syndrome".

The following incident took place at a party among peers in 2018. The planning committee had done its utmost to create a selection of themed bars. One such themed bar was inside a tent, furnished with carpets, cushions, and dimmed lighting. Malinowski's tent on the Trobriand Islands? A refugee camp facility? Once inside, all attendees were asked to write down a fieldwork experience, either experienced by themselves or by someone known to most. The notes were collected in a bowl. The following game consisted of guessing who the experience referred to: "Who was once hanging on a cliff after a landslide", "who unknowingly attended a party with narco lords", or "who was robbed at gunpoint outside his field residence", and so on. Conspicuously absent were questions such as "who was left sleepless for months after working in a refugee camp" or "who 
was on sick leave after carrying out fieldwork among human smugglers". People were surprisingly good at guessing whom each incident referred to, a fact I interpret as indicative of the rather high street value such stories have in research environments. But, also, telling of the fact that emotional stress management can take many forms, including performance, good company, and shared laughter. This, then, obviously leads to the question of the extent to which institutional cultures limit or enable attention to research-related emotional distress.

Not everyone buys into the "Indiana Jones syndrome". One midcareer researcher felt "totally misplaced" in settings cultivating this kind of "boyish attraction to danger". After years of working among asylum seekers and immigrants in prisons or detention centres, it was her experience that some male colleagues are attracted to what they believe is work among dangerous inmates:

I find that way of talking about the people we work with quite disturbing, enormously 'other-making'. It is making people far more dangerous than they are, or ever could be, and it results in a way of articulating otherness as something you cannot grasp unless you have been there, done drugs with your interlocutors, shared their weapons.

When asking if she had ever felt emotional distress during fieldwork, she elaborated: "While some of the people I've worked with have been convicted of violence or done other terrible things, only defining them by their criminal act and not taking other facets of their lives into account, including their boyishness, the everyday and the adventurous, the poetic and the inspirational, all the other things that go into a person ... to omit that disturbs me".

The point here is not to distinguish "hard-skinned" researchers from emotionally reflexive ones, nor to manshame male colleagues, or accuse feminist killjoys, and certainly not to argue for cancelling future parties and opportunities to relieve anxiety-provoking experiences. A good laugh among peers has often proved an effective way to start deeper and relevant discussions about working conditions. However, continuously casting the researcher as adventurous and daring (to not say self-promoting or selfaggrandising) contributes to upholding unhealthy institutional cultures as well as the co-creation of global distancing and no-go zones. 


\section{Contagious Field Sites, Empathy and Emotions}

An early career researcher conducting fieldwork in asylum centres connected the field site, the personal and the political in a different way: "In many ways, asylum centres are ideal places for conducting fieldwork. Nothing much is happening, most of the time it is pretty boring, and people have plenty of time to talk with you", she explained. But then she continued:

However, there is a sensory dimension connected to walking around in this boredom. The feeling that everything has stalled but meanwhile your interlocutors could receive a letter from the immigration authorities any day that changes everything. That so much is at stake ... it somehow becomes contagious ... that everything can go wrong [with the asylum application process] any moment ... I found it immensely stressful.

After ending a year of fieldwork, she fell apart. "When everything is so, yes, just shitty, and people are doing so badly and this becomes the norm, well then it becomes extremely difficult to leave the field. Because everything that I find problematic in relation to the handling of asylum seekers is somehow confirmed by my departure, right? And well, I just became very sad". The combination of exposure to human suffering and the "sorrow of parting" (Parvez 2018) simply became too much to bear.

Another researcher turned the question of emotional distress upsidedown by asking: "Wouldn't it be terribly disturbing if you were not affected? If you were not emotionally distressed? To see all that suffering without any reaction. Isn't that in fact a sign of psychopathy?" In her definition, watching and navigating human suffering undisturbed, without letting yourself be touched by it, would constitute a horrific fieldwork ideal. As emphasised by Kasper Hoffmann (2014), the proposition that fieldworkers can or should strive to set their personal histories aside-and thereby divest themselves of their values and prejudices in order to attain an objective understanding of their research subjects-is nothing short of an impossible empiricist dream.

\section{The Process of Writing}

Equally important, participants described how feelings of emotional distress "never end" but continue or reappear in the process of data processing, analysis, and writing: "I found it really difficult to get back 
to the taped interviews and read the transcriptions. In fact, I had to have another person transcribe the recordings, because I could hardly stand listening to them, even a year after my return from the field", a $\mathrm{PhD}$ researcher stated.

It is when I get back to the data that I feel vulnerable. And to this day I have a hard time sitting down to listen to the recordings ... it reminds me of how embedded I was and how focused I was on taking physical care of myself, you know: being able to turn the car 180 degrees in two seconds and flee and whatever you learn during those HEAT courses, while I did not consider the emotional damage that feelings of constant insecurity inflicted on me.

In her case too much, or too one-sided, institutional attention to physical security prevented her from grasping her emotional vulnerability.

When field notes or collected archival material contain traumatic human experiences, writing may become insuperable. The collision of pressure to disseminate, institutional demands around formats, and personal expectations contributes to the unbearable darkness of the writing process. Another PhD researcher commented: "Before I was just part of a research project, but you get the sense, well definitely the intense sense, that you need to publish. But here the emotional struggles became a block". In attempts to write she found it impossible to write "objectively", and objective was the standard she was encouraged to write by. "I had to sort of pull all the feelings out of it. And that was very difficult to do, and in the end also very unsatisfying".

A more experienced researcher described how hopelessness, despite years of engaging with the same field, crept under her skin: "I was trained to look for agency, and I have written about agency, but these days migrants are deported anyway". Thus, emotional distress related to writing is not limited to a possible traumatic experience of revisiting field notes and recordings. It is also embedded in the increasingly politicised environment circumscribing our research: "It is my experience that the migrants I work among have an increasingly hard time", she further explained. "When I started out 15 years ago, my interlocutors were granted residence status, some felt lonely and longed for somebody to talk to. And there I was. Today they can be deported at any time ... and it makes me feel powerless. To be witness to this development. What difference does it make that I write about it? Because their situation just 
gets worse and worse, across the board". To underscore the pervasive dilemmas related to writing she stated: "With the changing political situation I feel, well, that it doesn't help, in this political environment, to reveal in writing that the people I work with have agency, because it will only be used against them".

\section{Digital Availability}

Whereas digital technologies have expanded the ways research is carried out, including web-based interviewing and other forms of "netnography" (Kozinets 2015), it has also affected the relationship between researchers and research subjects. The fact that online sociality is multidirectional and increasingly accessible to the people we work with means that it is no longer the sole privilege of the researcher to reach out to interlocutors, as they are now available to interlocutors long after a research project ends. While this certainly democratises research processes and moves research towards more participatory and inclusive designs, it potentially poses an additional stress factor to those already mentioned above, especially if there is so little you can do to change the often dire circumstances our interlocutors find themselves in. As one senior researcher commented:

During the past few years, I have experienced a tremendous level of stress from constantly being in contact with my interlocutors. Hearing about their situation all the time, through WhatsApp, Messenger, phone calls. I constantly negotiate with myself whether I have to be on fieldwork all the time. What happens if I decide not to? I cannot afford to withdraw for a year and then go back when it suits me and say 'hey, let's resume contact', while they have had a miserable year.

A doctor's order to disconnect from communication with interlocutors during a three-month leave recharged her batteries enough to resume contact. Others talked about the cumulative effect of not handling their field and maintaining contact as well as previously, partly due to the perception that migrants and refugees face ever harsher conditions, partly because their own ability to make a difference has narrowed.

\section{Conclusion and Ways Ahead}


You will be changed by your research; that is one of the legacies. No, not necessarily turned into one of the walking wounded, but changed in ways that may not be readily or immediately apparent. The awareness of this - and of how the changes manifest across time and space - can make a difference while we conduct our research and when we return from our field sites and sit down to write. (Theidon 2014, 3)

This chapter has explored the difficulties of practicing emotions in the field and in research in general. To that end, I have outlined examples from the research participants' professional trajectories, as well as their reflections on these. One of the issues pertaining to fieldwork is that we never seem to have as much control over what is going on around us as we would sometimes like. Rather, we pretty much must go along with the flow of events surrounding us, which when working in insecure places often provokes anxiety and, when working among people in seemingly hopeless situations, impacts our emotional well-being. None of the participants in this study suggest that this can, or should be, avoided. On the contrary, they have used their sometimes hard-earned personal experiences to reflect creatively: on what can be done to better prepare younger colleagues for their first fieldwork and protect more experienced researchers from compassion fatigue or burnout; on how to enable institutional structures to provide better practices; and on how not to, themselves, contribute further to the co-creation of "no-go zones", or the nourishing of an "Indiana Jones" culture.

It is surely essential to acknowledge emotion as inherent in any research practice. But we must also promote researcher vulnerability as a valuable resource and not something to be prevented or avoided. One way to institutionally support this challenge would be to understand emotional counselling as a natural component of challenging research circumstances, rather than as an offer of treatment to those who return with traumatic symptoms. Potentially emotionally challenging situations should therefore be included in project design and methodology and form part of the evaluation made by ethics boards and the supervision given to younger scholars by their more experienced senior colleagues. One way to facilitate such institutional change, several younger colleagues have reminded me, is the power of the example: experienced researchers could certainly be more open about their own past and present vulnerabilities. For a start we could let go of the Indiana Jones culture and collectively search for more 
respectful, empathetic - and in the end more effective-ways of building trust with our interlocutors.

Time is a precious resource, especially when seeking to generate as much knowledge as possible while in the field. Participants in this study nevertheless pointed to the need for relaxation and leisure activities when conducting fieldwork over long periods of time. They also stressed the importance of maintaining research diaries, both as a cathartic tool for recording personal fears and shortcomings (Browne 2013), but also for expressing personal feelings of guilt, apprehension, and worry. Apart from serving as a logging device or a mere self-investigatory outlet, field diaries can then be used more explicitly to examine the ways our personal challenges and emotions impact the research process and its outcomes (Punch 2012). Those who have kept such diaries have moreover found them extremely helpful when later experimenting with more dialogical or creative forms of writing.

The attitude to sometimes dreaded ethical review boards and mandatory debriefing after completed fieldwork was more divided. With regard to the first, several have experienced that it is institutional interest rather than employee well-being that is protected. About debriefing, some find that in the best of cases it makes little difference, in the worst of cases it leads to retraumatisation. Others have found available debriefing structures helpful, but note that they ought not to be standardised, nor reflect institutional power structures. Few wish to involve individuals with power over their present and future work opportunities (directors, supervisors, human resource personnel) in such structures, but see potential in creating "safe groups" that meet regularly, can be contacted during fieldwork, and always when someone comes back from the field.

Interestingly, instances of compassion fatigue seem to have as much to do with the prevailing migration policy discourse in the Global North as with overexposure to misery and uphill struggles encountered in the field. This suggests that "compassion fatigue" is not necessarily a sign of a lack of compassion, but rather-and on top of the current emotional politics in research environments-is reflective of the politicised context in which contemporary migration research is carried out.

Stefanie Kappler (2021) reminds us that solidarity is a powerful response to the power differentials that emerge from different levels of privilege. Privilege not only determines mobility-who has permission to move in and out of which spaces-but also what researchers are willing 
and capable of observing and writing about, and for how long. This obviously makes it crucial to avoid making empty promises to the people we engage with, but perhaps also to be realistic about how much we can do. Ultimately, it offers an opportunity to rethink and push for more ethical—and more equal—research practices, or, as suggested by Abedi et al. (2020), new, non-exploitative forms of knowledge production.

\section{Note}

1. For a more explicit focus on vicarious trauma among researchers, I refer to Appelbaum (2008), Coles et al. (2014), Plakas (2018), Plüg and Collins (2018) and Sloan et al. (2019).

\section{BIBLIOGRAPHY}

Abedi Dunia, Oscar, Stanislas Bisimwa, Elisée Cirhuza, Maria Eriksson Baaz, John Ferekani, Pascal Imili, Evariste Kambale et al. 2019. "Moving Out of the Backstage: How Can We Decolonialize Research?" Accessed January 7, 2021. https://thedisorderofthings.com/2019/10/22/moving-out-of-thebackstage-how-can-we-decolonize-research/.

Abedi, Oscar, Maria Eriksson Baaz, David Mwambari, Swati Parashar, Anju Oseema Maria Toppo, and James Vincent. 2020. "The Covid-19 Opportunity: Creating More Ethical and Sustainable Research Practices.” Items, Insights from the Social Sciences. Accessed January 7, 2021. https://items. ssrc.org/covid-19-and-the-social-sciences/social-research-and-insecurity/thecovid-19-opportunity-creating-more-ethical-and-sustainable-research-practi ces/.

Åhåll, Linda. 2018. "Affect as Methodology: Feminism and the Politics of Emotion." International Political Sociology 12 (1): 36-52.

Ahmed, Sara. 2014. The Cultural Politics of Emotion. 2nd ed. Edinburgh: Edinburgh University Press.

Andersson, Ruben. 2019. No Go World: How Fear is Redrawing our Maps and Infecting our Politics. Oakland: University of California Press.

Appelbaum, Jenna. 2008. "Trauma and Research: Bearing Responsibility and Witness." Women's Studies Quarterly 36 (1): 272-275.

Bosworth, Mary. 2017. "Secondary Trauma and Research." Accessed January 7, 2021. https://www.law.ox.ac.uk/research-subject-groups/centre-crimin ology/centreborder-criminologies/blog/2017/10/secondary-trauma.

Browne, Brendan Ciaran. 2013. "Recording the Personal: the Benefits in Maintaining Research Diaries for Documenting the Emotional and Practical 
Challenges of Fieldwork in Unfamiliar Settings." International Journal of Qualitative Methods 12 (1): 420-435.

Carling, Jørgen. 2002. "Migration in the Age of Involuntary Immobility: Theoretical Reflections and Cape Verdian Experiences." Journal of Ethnic and Migration Studies 28 (1): 5-42.

Castellanos, M. Bianet. 2019. "Introduction." In Detours: Travel and the Ethic of Research in the Global South, edited by M. Bianet Castellanos, 3-18. Tucson, AZ: The University of Arizona Press.

Coles, Jan, Jill Astbury, Elizabeth Dartnall, and Shaznee Limjerwala. 2014. "A Qualitative Exploration of Researcher Trauma and Researchers' Response to Investigating Sexual Violence." Violence Against Women 20 (1): 95-117.

Distretti, Emilio. 2020. "Enforced Disappearance and Border Deaths Along the Migrant Trail." In Border Deaths: Causes, Dynamics and Consequences of Migration-related Mortality, edited by Paolo Cuttitta, and Tamara Last. Amsterdam: Amsterdam University Press.

Felbab-Brown, Vanda. 2014. "Security Considerations for Conducting Fieldwork in Highly Dangerous Places or on Highly Dangerous Subjects." Accessed January 7, 2021. http://webarchive.ssrc.org/working-papers/DSD_Resear chSecurity_03_Felbab-Brown.pdf.

Fleetwood, Jennifer. 2009. "Emotional Work: Ethnographic Fieldwork in Prisons in Ecuador." eSharp, Special Issue: Critical Issues in Researching Hidden Communities, 28-50. Accessed August 1, 2021. https://core.ac.uk/dow nload/pdf/84339424.pdf.

Goldstein, Daniel M. 2014. "Qualitative Research in Dangerous Places: Becoming an Ethnographer of Violence and Personal Safety." Accessed January 7, 2021. http://webarchive.ssrc.org/working-papers/DSD_Resear chSecurity_01_Goldstein.pdf.

Grimm, Jannis J, Kevin Koehler, Ellen M. Lust, Ilyas Saliba, and Isabell Schierenbeck. 2020. Safer Field Research in the Social Sciences. London: Sage Publications.

Hoffmann, Kasper. 2014. Caught between Apprehension and Comprehension: Dilemmas of Immersion in a Conflict Setting. Copenhagen: DIIS Working Paper (No. 9).

Hugman, Richard, Eileen Pittaway, and Linda Bartolomei. 2011. "When 'Do No Harm' is Not Enough: the Ethics of Research with Refugees and Other Vulnerable Groups." British Journal of Social Work 41 (7): 1271-1287.

Kalinga, Chisomo. 2019. "Caught Between a Rock and a Hard Place: Navigating Global Research Partnerships in the Global South as an Indigenous Researcher." Journal of African Cultural Studies 31 (3): 270-272.

Kappler, Stefanie. 2021. "Privilege." In The Companion to Peace and Conflict Fieldwork, edited by Roger Mac Ginty, Roddy Brett, and Birte Vogel. London: Palgrave Macmillan. 
Khosravi, Shahram. 2018. After Deportation: Ethnographic Perspectives. Basingstoke: Palgrave Macmillan.

Kozinets, Robert. 2015. Netnography: Redefined. London: Sage Publications.

Kristensen, Nanna Hauge. 2017. "Det Grænseoverskridende Feltarbejde." Jordens Folk 3-4 (52): 70-77.

Lake, Milli, and Sarah E. Parkinson. 2017. "The Ethics of Fieldwork Preparedness." Accessed January 7, 2021. https://politicalviolenceataglance.org/ $2017 / 06 / 05 /$ the-ethics-of-fieldwork-preparedness/.

Last, Tamara. 2020. "Secondary Trauma Among Researchers: Implications of Traumatogenic Research in Archives." SAGE Research Methods Cases. Accessed January 7, 2021. https://doi.org/10.4135/9781529708462.

Lubkemann, Stephen C. 2008. "Involuntary Immobility: on a Theoretical Invisibility in Forced Migration Studies.” Journal of Refugee Studies 21 (4): 454-475.

Mac Ginty, Roger, Roddy Brett, and Birte Vogel (eds.). 2021. The Companion to Peace and Conflict Fieldwork. London: Palgrave Macmillan.

Mackenzie, Catriona, Christopher McDowell, and Eileen Pittaway. 2007. “Beyond 'Do No Harm': The Challenge of Constructing Ethical Relationships in Refugee Research." Journal of Refugee Studies 20 (2): 299-319.

Marinovich, Greg, and João Silva. 2000. The Bang-Bang Club: Snapshots from a Hidden War. New York: Basic Books.

Martin-Ortega, Olga, and Johanna Helman. 2009. "There and Back: Surviving Research in Violent and Difficult Situations." In Surviving Field Research: Working in Violent and Difficult Situations, edited by Chandra Lekha Shiram, John C. King, Julie A. Mertus, Olga Martin-Ortega, and Johanna Herman. Abingdon, Oxon: Routledge.

McLean, Athena (with Annette Leibing). 2011. "Ethnography and SelfExploration." Medische Antropologie 23 (1): 183-201.

Menjívar, Cecilia, Marie Ruiz, and Immanuel Ness. 2019. The Oxford Handbook of Migration Crises. New York: Oxford University Press.

Môcnik, Nena. 2020. "Rethinking Exposure to Trauma and Self-Care in Fieldwork-Based Social Research: Introduction to Special Issue." Social Epistemology 34 (1): 1-11.

Parvez, Z. Fareen. 2018. "The Sorrow of Parting: Ethnographic Depth and the Role of Emotions." Journal of Contemporary Ethnography 47 (4): 454-483.

Plakas, Christina. 2018. "Burnout, Compassion Fatigue, and Secondary Traumatic Stress Among Humanitarian Aid Workers in Jordan.” Accessed January 7, 2021. https://www.researchgate.net/publication/328685237_Burnout_C ompassion_Fatigue_and_Secondary_Traumatic_Stress_Among_Humanitar ian_Aid_Workers_in_Jordan. 
Plüg, Simóne, and Anthony Collins. 2018. "It Hurts to Help: Vicarious Trauma in Sensitive Research and Community Projects in South Africa." The Australian Community Psychologist 29 (1): 22-35.

Punch, Samantha. 2012. "Hidden Struggles of Fieldwork: Exploring the Role and Use of Field Diaries." Emotion, Space and Society 5 (2): 86-93.

Richmond, Anthony H. 1994. Global Apartheid: Refugees, Racism and the New World Order. Oxford: Oxford University Press.

Shah, Sonia. 2020. The Next Great Migration: The Story of Movement on a Changing Planet. London: Bloomsbury.

Shiram, Chandra Lekha, John C. King, Julie A. Mertus, Olga Martin-Ortega, and Johanna Herman (eds.). 2009. Surviving Field Research: Working in Violent and Difficult Situations. Abingdon, Oxon: Routledge.

Sloan, Katie, Jennifer Vanderfluit, and Jennifer Douglas. 2019. "Not 'just my problem to handle': Emerging Themes on Secondary Trauma and Archivists." Journal of Contemporary Archival Studies 6: 20.

Stepputat, Finn, and Ninna Nyberg Sørensen. 2014. "Sociology and Forced Migration." In The Oxford Handbook of Refugee and Forced Migration Studies, edited by Elena Fiddian-Qasmiyeh, Gil Loescher, Katy Long, and Nandy Sigona. Oxford: Oxford University Press.

Sørensen, Ninna Nyberg, and Laura Huttunen. 2020. "Missing Migrants and the Politics of Disappearance in Armed Conflicts and Migratory Contexts." Ethnos. https://doi.org/10.1080/00141844.2019.1697333.

Sørensen, Ninna Nyberg, and Sine Plambech. 2019. Global Perspectives on Humanitarianism. DIIS Report No. 03. Copenhagen: Danish Institute for International Studies.

Theidon, Kimberly. 2014. "How was your trip? Self-Care for Researchers Working And Writing on Violence." Accessed January 7, 2021. http://web archive.ssrc.org/working-papers/DSD_ResearchSecurity_02_Theidon.pdf.

Turner, Sarah. 2010. "Research Note: The Silenced Assistant. Reflections of Invisible Interpreters and Research Assistants." Asia Pacific Viewpoint 51 (2): 206-219.

Woon, Chih Yuan. 2013. "For 'Emotional Fieldwork' in Critical Geopolitical Research on Violence and Terrorism." Political Geography 33 (1): 31-41. 
Open Access This chapter is licensed under the terms of the Creative Commons Attribution 4.0 International License (http://creativecommons.org/licenses/ by $/ 4.0 /$ ), which permits use, sharing, adaptation, distribution and reproduction in any medium or format, as long as you give appropriate credit to the original author(s) and the source, provide a link to the Creative Commons license and indicate if changes were made.

The images or other third party material in this chapter are included in the chapter's Creative Commons license, unless indicated otherwise in a credit line to the material. If material is not included in the chapter's Creative Commons license and your intended use is not permitted by statutory regulation or exceeds the permitted use, you will need to obtain permission directly from the copyright holder.

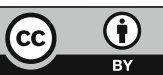

